\title{
The Power of Facts
}

\section{Dear Reader,}

The relationship between OEM and supplier is sometimes far from easy. We were recently reminded of this when the dispute between Volkswagen and the Prevent group companies emerged. While the conflict itself was resolved fairly soon, none of the contracting parties won.

The suppliers involved defended themselves - which is not unusual in the industry - but risk losing out on lucrative contracts in future because they now considered a hazard. Conversely, while the OEM ultimately made its presence felt, its image took a battering in the process.

Thirdly, however - and this is the key point - this dispute demonstrates the extent to which carmakers depend on their suppliers. In recent years manufacturers have increasingly delegated development work to their suppliers and service providers, often with cost savings in mind. Consequently, as well as generating around $70 \%$ of the added value of a car, external partners are also crucial to the innovative power of OEMs. They benefit from the growing need for networked development in vehicle and drivetrain design, which are expected to deliver system context solutions. It is a fact that no present-day carmaker can get a single vehicle on the road without its suppliers and service providers. Moreover, this actual power will continue to grow, particularly in upcoming key fields such as battery technology, electrified powertrains and autonomous cars.
With this in mind, OEMs are very lucky that, with a few exceptions, there is a huge disparity between the strategic importance of German automotive suppliers and their public profile, as a recent study conducted by the Nuremberg market research institute Puls confirmed. Even so, a genuine partnership of equals would make sense, in light of the major relevance of suppliers and service providers.
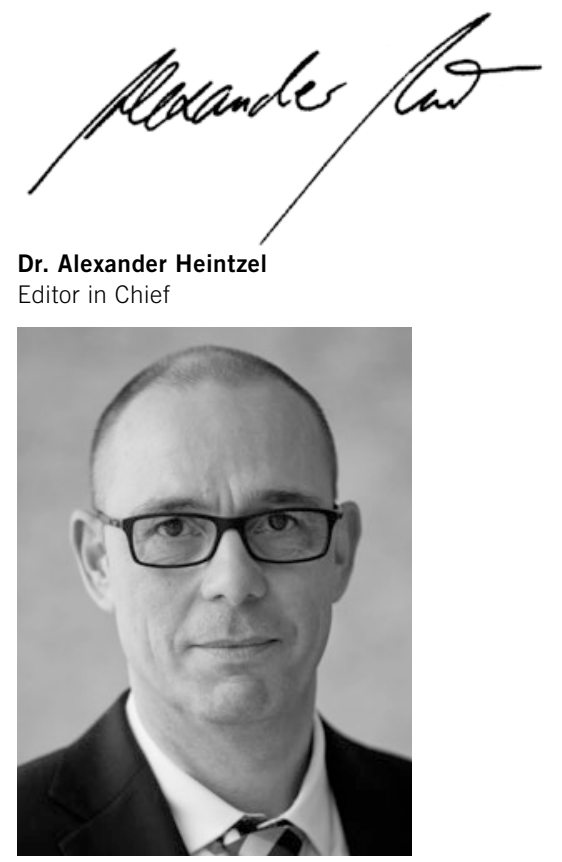